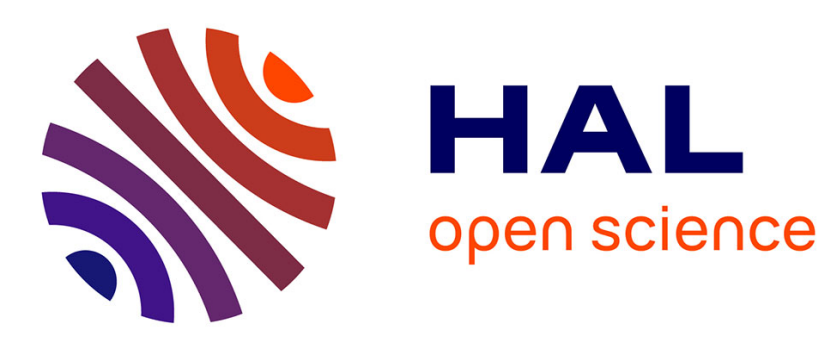

\title{
Rare cutaneous toxicity of immune checkpoint inhibitors: A case of durvalumab-induced dermatomyositis
}

Cyrille Coustal, Aurélie Du Thanh, François Roubille, Eric Assenat, Alexandre T.J. Maria

\section{To cite this version:}

Cyrille Coustal, Aurélie Du Thanh, François Roubille, Eric Assenat, Alexandre T.J. Maria. Rare cutaneous toxicity of immune checkpoint inhibitors: A case of durvalumab-induced dermatomyositis. European Journal of Cancer, 2021, 155, pp.25-27. 10.1016/j.ejca.2021.06.031 • hal-03311531

\section{HAL Id: hal-03311531 \\ https://hal.science/hal-03311531}

Submitted on 2 Aug 2021

HAL is a multi-disciplinary open access archive for the deposit and dissemination of scientific research documents, whether they are published or not. The documents may come from teaching and research institutions in France or abroad, or from public or private research centers.
L'archive ouverte pluridisciplinaire $\mathbf{H A L}$, est destinée au dépôt et à la diffusion de documents scientifiques de niveau recherche, publiés ou non, émanant des établissements d'enseignement et de recherche français ou étrangers, des laboratoires publics ou privés. 


\title{
Rare cutaneous toxicity of immune checkpoint inhibitors: A case of durvalumab-induced dermatomyositis
}

\author{
Cyrille Coustal $^{\mathrm{a}}$, Aurélie Du Thanh ${ }^{\mathrm{b}}$, François Roubille ${ }^{\mathrm{c}}$, Eric Assenat ${ }^{\mathrm{d}}$, \\ Alexandre T.J. Maria ${ }^{a, e, *}$
}

a Department of Internal Medicine, Multi-Organic Diseases, Local Referral Center for Rare Auto-immune Diseases, Montpellier University Hospital, Montpellier, France

${ }^{\mathrm{b}}$ Department of Dermatology, Montpellier University Hospital, Montpellier, France

c Department of Cardiology, Montpellier University Hospital, Montpellier, France

d Department of Oncology, Saint Eloi Hospital, Montpellier University Hospital, Montpellier, France

${ }^{\mathrm{e}}$ Institute of Regenerative Medicine and Biotherapy, Institut national de la santé et de la recherche médicale U1183,

Montpellier, France

\section{KEYWORDS}

Immune checkpoint

inhibitors;

Hepatocarcinoma;

Paraneoplastic

syndrome;

Dermatomyositis;

Myasthenia gravis

Dear editor,

* Corresponding author: Internal Medicine, Multi-Organic Diseases, Saint Eloi Hospital, Montpellier University Hospital, 80 avenue Augustin-Fliche, 34295, Montpellier Cedex 5, France.

E-mail address: a-maria@chu-montpellier.fr (A.T.J. Maria).

Cutaneous reactions are among the most frequent immune-related adverse events (irAEs) with immune checkpoint inhibitor (ICI) therapies targeting cytotoxic T-lymphocyte antigen 4 or programmed death (ligand)-1 (PD-1/PD-L1). Most reactions present as maculopapular rash, pruritus, vitiligo, lichen, or bullous diseases. There are few observations about sarcoidosis, lupus, or sclerosis. We report here a dermatomyositis revealed by antiPD-L1 immunotherapy. 

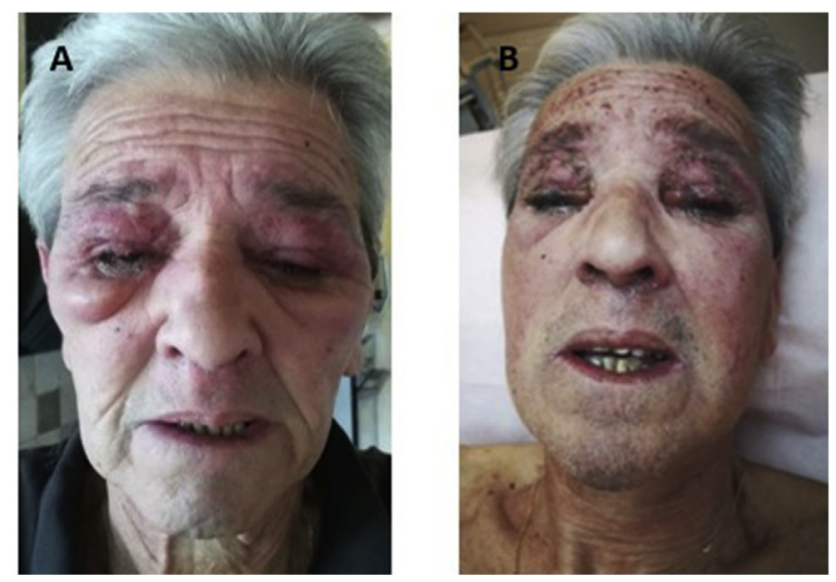

Fig. 1. Clinical features. (A) Voluminous oedema of eyelids. (B) Superficial erosions on heliotrope rash few days later.

A 66-year-old man was referred to our hospital for a stage B hepatocellular carcinoma (HCC) with three intrahepatic lesions, on a CHILD A5 liver, and AFP-score of 6 . He had no personal or familial history of autoimmunity, but his brothers were diagnosed with haemochromatosis. Because hepatocarcinoma was unresectable, he underwent two chemoembolisations with idarubicin, followed by an infusion of durvalumab. Eighteen days later, he was referred to dermatology department for the rapid onset of symmetrical erythematous oedema of the eyelids, associated with subsequent erosive lesions that extended to the forehead (Fig. 1), and ulcerative cheilitis. No other lesion was present upon comprehensive skin and mucosae examination, nor pathological lymph nodes, nor myositis symptoms. Herpes simplex virus (HSV) infection was ruled out and $0.5 \mathrm{mg} / \mathrm{kg}$ oral prednisone was prescribed. Upon a recent sun exposure, idarubicin phototoxicity was first suspected. Two days later, he reported a slight improvement, and received a second infusion of durvalumab. However, $48 \mathrm{~h}$ later, he presented to the emergency ward for a left leg oedema, with negative screening for venous thrombosis. Clinical examination revealed proximal muscular weakness, while creatine kinase reached the level of $3816 \mathrm{UI} / 1(20 \mathrm{~N})$, with myoglobin level of $2580 \mathrm{UI} / 1(35 \mathrm{~N})$ and a mildly elevated troponin (Troponin T-HS $130 \mathrm{ng} / \mathrm{l}$ ). Immunology revealed antinuclear antibodies titre of $1 / 1280$, and positivity of antitranscriptional intermediary factor-1-gamma (antiTIF1 $\gamma$ ) autoantibodies, consistent with the diagnosis of dermatomyositis. Cardiac magnetic resonance imaging excluded myocarditis, while angiography revealed a severe coronary artery disease with mainly a significant stenosis on the left main coronary artery. Because of immune haemolytic anaemia and thrombocytopaenia, angioplasty was postponed and he received three pulses of methylprednisolone with subsequent oral prednisone $1 \mathrm{mg} / \mathrm{kg}$. Few days later, he exhibited a septic discharge on the peripherally inserted central catheter of the left arm, which lead us to introduce antibiotics (daptomycin/cefazolin/ gentamicin). Unfortunately, he presented sudden respiratory failure complicated by cardiac arrest a few hours later and died from subsequent multiorgan failure in spite of adapted reanimation. Post-mortem analyses revealed positivity for anti-acetylcholine receptor antibodies, leading to the diagnosis of ICI-induced myasthenia gravis (MG). Myasthenic crises may be a possible explanation for the sudden respiratory distress that may have been triggered by minoglycosides.

A literature review in 2018 found 10 cases of $\mathrm{HCC}$ associated with dermatomyositis [1], an inflammatory myopathy which is known to be associated with cancer in up to $20-30 \%$ of cases (paraneoplastic syndrome). This association is strongly dependent on the subtype of myopathy-specific autoantibody involved, like antiTIF1 $\gamma$. Interestingly, there is a literature supporting the role of TIF1 $\gamma$ in the regulation of transforming growth factor-beta superfamily signalling, which is involved in the control of cellular proliferation, and thereby in cancer inhibition. A study even found a reduced expression of TIF1 $\gamma$ in HCC, especially in advanced HCC [2]. The authors mentioned a poor prognosis of decreased level of TIF1 $\gamma$, as a significant risk factor for recurrence, and associated with more metastases [2].

There are few cases of ICI-induced dermatomyositis, and only one with anti-TIF1 $\gamma$ antibodies, triggered by ipilimumab $[3,4]$. The clinical signs were unusual, leading us to misdiagnose, because if heliotrope rash of the upper eyelids is classical, this intensity remains exceptional. We were also surprised by the migrating oedema of the limbs that the patient presented. Unilateral oedema of the limbs is uncommon, but possible, in inflammatory myopathy, with a recent article outlining the association with the antibodies of dermatomyositis, rather than other inflammatory myopathies [5]. Interestingly, ICI-induced myositis may also be associated with MG and myocarditis ( $3 \mathrm{M}$ syndrome) in $11.9 \%$ and $11.3 \%$ of cases respectively [6], with worse prognosis and higher mortality rates. Of note, paraneoplastic syndromes are known to be a risk factor for irAEs [7].

As a conclusion, we describe for the first time the cooccurrence of TIF-1 gamma dermatomyositis and $\mathrm{MG}$ under anti-PD-L1 therapy with fatal outcome in a patient with hepatocarcinoma. This unfortunate observation prompts to more vigilance in the follow-up of patients under ICIs, and systematic biological screening on creatine kinase. Immunological work-up should also include anti-acetylcholine receptor antibodies. 


\section{Conflict of interest statement}

The authors declare the following financial interests/ personal relationships which may be considered as potential competing interests: ATJM received fees from Abbvie, Actelion, CSL Behring, Experf, Novartis, and Shire and declares speaking fees from Astra-Zeneca, Sanofi-Aventis, and BMS in the last 5 years. Other authors declare they have no known competing financial interests.

\section{References}

[1] Han J, Wang S, Kwong TNY, Liu J. Dermatomyositis as an extrahepatic manifestation of hepatitis B virus-related hepatocellular carcinoma: a case report and literature review. Medicine (Baltim) 2018;97(33):e11586. https://doi.org/10.1097/MD.0000000000011586.

[2] Yu C, Ding Z, Liang H, Zhang B, Chen X. The roles of TIFl $\gamma$ in cancer. Front Oncol 2019;9:979. https://doi.org/10.3389/fonc.2019. 00979.
[3] Kadota H, Gono T, Shirai Y, Okazaki Y, Takeno M, Kuwana M. Immune checkpoint inhibitor-induced myositis: a case report and literature review. Curr Rheumatol Rep 2019 Feb 21;21(4):10. https: //doi.org/10.1007/s11926-019-0811-3.

[4] Yamaguchi Yasuyuki, Abe Riichiro, Haga Naoya, Shimizu Hiroshi. A case of drug-associated dermatomyositis following ipilimumab therapy. Eur J Dermatol 2016;26(3):320-1. https://doi.org/10.1684/ejd.2016.2770.

[5] Duchesne M, Leonard-Louis S, Landon-Cardinal O, et al. Oedematous myositis: a clinical presentation first suggesting dermatomyositis diagnosis. Brain Pathol April 22, 2020. https: //doi.org/10.1111/bpa.12844.

[6] Nguyễn T, Maria ATJ, Ladhari C, et al. Rheumatic disorders associated with immune checkpoint inhibitors: what about myositis? An analysis of the WHO's adverse drug reactions database. Ann Rheum Dis February 17, 2020. https://doi.org/10.1136/annrheumdis2020-217018.

[7] Manson G, Maria ATJ, Poizeau F, et al. Worsening and newly diagnosed paraneoplastic syndromes following anti-PD-1 or antiPD-L1 immunotherapies, a descriptive study. J Immunother Cancer 2019;7:337. https://doi.org/10.1186/s40425-019-0821-8. 